\title{
DENTOSKELETAL EFFECTS FOLLOWING TWIN-BLOCK FUNCTIONAL TREATMENT OF SKELETAL CLASS II MALOCCLUSION ACCOMPANIED WITH LOW-LEVEL LASER THERAPY: A PROSPECTIVE CLINICAL EVALUATION
}

\author{
Mahmoud Abdel Hameed Mohamed, Khaled Farouk Abdallah, ${ }^{* *}$ Farouk Ahmed Hussein ${ }^{* * * *}$
}

\begin{abstract}
Objective: The current prospective study evaluated the dentoskeletal effects subsequent to Twin-Block (TB) functional treatment of skeletal Class II malocclusion accompanied with low-level laser therapy (LLLT).

Materials and methods: Twenty eight pre-pubertal patients, 14 boys and 14 girls were randomly allocated to control (mean initial age $10.64 \pm 1.36$ years) and laser groups (mean initial age $10.55 \pm 1.45$ years). All patients treated with TB appliance where Gallium Aluminum Arsenide diode laser applied in one group weekly around condylar region for 12 sessions in three months with parameters; continuous mode, $635 \mathrm{~nm}, 50 \mathrm{~mW}, 4.5 \mathrm{~J} / \mathrm{cm}^{2}, 45 \mathrm{~seconds} /$ point, and $11.25 \mathrm{~J}$ total dose per side. Dentoskeletal variables were analyzed and compared within and between both groups via Cone Beam Computed Tomography (CBCT) images before (T1) and after functional therapy (T2).
\end{abstract}

Results: Within each group, TB therapy resulted in significant mandibular skeletal changes $(\mathrm{p}<0.001)$ in both dimensions and positions with an improved skeletal profile in anteroposterior and vertical directions with substantial dentoalveolar changes $(\mathrm{p}<0.001)$. However, comparison of dentoskeletalT1-T2 changes between both groups showed non- significant differences $(\mathrm{p}>0.05)$.

Conclusions: Combination of LLLT, with the current parameters and protocol, accomplished no considerable dentoskeletal effects subsequent to functional orthopaedic treatment of skeletal Class II malocclusion with TB appliance.

KEYWORDS: Low-level laser therapy, Skeletal Class II malocclusion, Twin-block Appliance, Dentoskeletal parameters, Cone Beam Computed Tomography

\section{INTRODUCTION}

Skeletal Class II malocclusion is one of the most common problems in orthodontic practice that are often due to mandibular deficiency. Forthe treatment of those patients with mandibular retrognathia, different removable or fixed functional appliances have been used to improve and /or redirect mandibular growth in a favorable direction ${ }^{(1-3)}$. In the last 10 years, the Twin-Block (TB) functional appliance developed by William Clark ${ }^{(4)}$ has been the most popular removable functional device.

* Dentist, Ministry of Health, Egypt, MSc student, Department of Orthodontics, Faculty of Dental Medicine (Boys), Al-Azhar University, Cairo, Egypt

** Lecturer, Department of Orthodontics, Faculty of Dental Medicine (Boys), Al-Azhar University, Cairo, Egypt *** Associate Professor \& Acting Chairman, Department of Orthodontics, Faculty of Dental Medicine (Boys), Al-Azhar University, Cairo, Egypt.

- Corresponding author: dr.farokahmed@azhar.edu.eg

DOI: 10.21608 /ajdsm.2020.31347.1064 
Several clinical studies have been carried out to evaluate the skeletal and dentoalveolar changes associated with TB appliances subsequentto treatment of Class II malocclusion ${ }^{(5-16)}$.However, functional orthopedic treatment of Class II malocclusions is a matter of ongoing controversy given the lack of consensus regarding the possibility of stimulating mandibular growth in a predictable manner. Although there were promising findings of increases of mandibular size in animal experimental models as well as in humans, others have failed to demonstrate any consistent changes in clinical settings and were unable to make changes in the underlying skeletal pattern ${ }^{(2)}$.

Indeed, the effectiveness of mandibular orthopedic management depends on the ultimate synergy between treatment and growth, especially in individuals who are undergoing their pubertal growth spurt. Therefore, it is assumed that the success of Class II treatment with mandibular deficiency depends on the ability of functional appliances to encourage condylar growth ${ }^{(3)}$.

Nevertheless, the duration of functional treatment of skeletal Class II usually varies from 6 to 24 months. One of the main concerns of orthodontists for decades is to reduce the treatment time to minimize the possible detrimental effects and increase patient compliance ${ }^{(17)}$.

Different techniques such as ultrasound and laser application have been used to reduce the time of functional treatment and to stimulate condylar growth in experimental animals ${ }^{(17-21)}$. Lately, Lowlevel laser therapy (LLLT), in the orthodontic field, has been demonstrated to be efficient in biomodulation, with inhibitory effects for analgesia and with stimulating action for tissue repair ${ }^{(22)}$. These effects were proposed to be due to the capacity of LLLT to accelerate metabolic changes and to promote faster bone remodeling, both necessary for orthodontic tooth movement ${ }^{(22)}$. As well, LLLT was used to enhance bone healing after fracture and mandibular distraction osteogenesis ${ }^{(23)}$.
Taking into account the proposed positive effects of LLLT concerning bone remodeling and the deficient human reports in this regard, it was a matter of interest to evaluate three-dimensionally the possible dentoskeletal effects subsequent to TB functional treatment of skeletal Class II malocclusion accompanied with LLLT.

\section{MATERIALS AND METHODS}

The study protocol was approved by Institutional Review Board and the Ethical Research Committee of Al-Azhar University, Cairo, Egypt (Registration No. orthod._10Med. Research._LLLT.TMJ. Class II._0000010). This prospective study was carried out from December 2017 to August 2019 on a total sample of 28 patients, 14 boys and 14girls, ranged in age from 9-12 years who were randomly selected from the Department of Orthodontics, Faculty of Dental Medicine (Boys), Al-Azhar University, Cairo, Egypt. The objectives of study and the treatment plan were explained for patients and their guardians and informed written consents were signed before commencing the study.

The patients selected for this study had met the following criteria: Skeletal Class II $\left(\mathrm{ANB}^{\circ}>5^{\circ}\right)$ with normal maxilla $\left(\mathrm{SNA}^{\circ}=82^{\circ} \pm 4^{\circ}\right)$ and retrognathic mandible $\left(\mathrm{SNB}^{\circ}<78^{\circ}\right)$; Overjet greater than $5 \mathrm{~mm}$; minimal crowding in dental arches $(\leq 3 \mathrm{~mm})$; the lower incisors should be in average inclination or slightly retroclined; all the patients were in stages II and III based on the modified cervical vertebral maturation stages (CVMS).

The following exclusion criteria were applied: previous history of orthodontic treatment; congenitally missing or extracted permanent teeth; posterior cross bites or severe maxillary transverse deficiency; severe facial asymmetry determined by clinical or radiographic examination; poor oral hygiene; systemic diseases that may affect the treatment results. 
The selected sample was randomly divided into two equal groups, according to laser intervension. The process of randomization and group allocation was undertaken using online software (http://www. graphpad.com/quickcalcs/index.com) 14 patients in laser group and 14 patients in control group. All patients participated in this study were treated according to the decided treatment plan with a modified Twin-block (TB) appliance according to Clark $^{(4)}($ Fig.1). The patients were instructed to wear the appliance $24 \mathrm{~h} /$ day and they were followed once every 4 weeks. The anteroposterior dental arch relationship was checked with and without the appliance during each appointment.

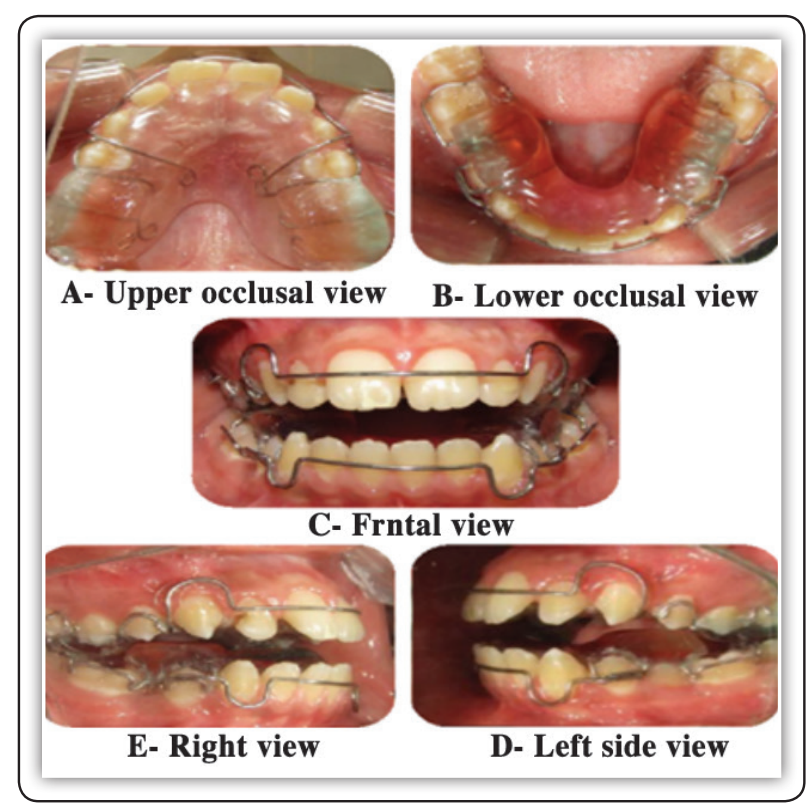

FIG (1) Twin-Block appliance.

Patients in the laser group $(n=14)$ were treated with TB functional appliance combined with lowlevel laser therapy (LLLT)where as those in the control group $(n=14)$ were treated with the same functional appliance but without LLLT. In the laser group, a LLLT was applied by the same operatorvia a semiconductor Gallium Aluminum Arsenide diode laser (SMART ${ }^{\mathrm{M} P R O}$, LASOTRONIX, Poland) with set parameters; $635 \mathrm{~nm}$ wavelength, continuouswave mode, $50 \mathrm{mw}$ power output, $4.5 \mathrm{~J} / \mathrm{cm}^{2}$ energy density, total dose of $11.25 \mathrm{~J} /$ side, 45 seconds/ point, and $8 \mathrm{~mm}$ fiber optic tip diameter.

A protocol for relief of temporomandibular joint disorders (TMD) was used in contact with the skin at five points located within the TMJ area: lateral point (LP), superior point (SP), anterior point (AP), posterior point (PP), and posterior- inferior point (PIP) of the condylar position ${ }^{(24,25)}$. The laser was applied according to the previous parameters in both right and left sides (Fig.2), and this protocol was repeated weekly for three months. Precautions were taken before laser application.

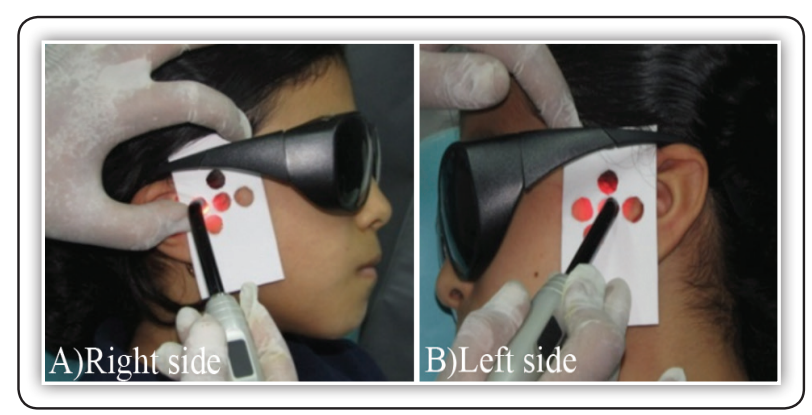

Fig (2) LLLT application at five points located within the TMJ area on both sides of a female patient.

Routine orthodontic records were taken for each patient before and after treatment. Additionally, Cone Beam Computed Tomography (CBCT) was taken before treatment (T1) and 9 months after completion of orthopedic phase (T2) in both groups, with and without LLLT. Constructed lateral cephalometric radiographs were obtained from CBCT images to evaluate the changes in the dentoskeletal parameters in both groups. Several dentoskeletal reference points and landmarks were used in study in both groups. In addition, several reference lines and planes were constructed (Table1) ${ }^{(5,6)}$. 
TABLE (1): Reference lines, planes and dentoskeletal landmarks used in the study ${ }^{(5,6)}$.

\begin{tabular}{|l|l|}
\hline Landmark/line & \multicolumn{1}{c|}{ Definition } \\
\hline Nasion (N) & The most anterior midpoint of the frontonasal suture. \\
\hline Sella (S) & The centeral point of the pituitary fossa in the middle cranial fossa \\
\hline Orbitale (Or) & The most inferior point of each infra-orbital rim. \\
\hline Subspinale (A) & The deepest midpoint of the maxillary anterior surface. \\
\hline Supramemtale (B) & The deepest midpoint of the mandibular anterior surface. \\
\hline Gonion (Go) & $\begin{array}{l}\text { The right and left midpoint on the angle of the mandible, halfway between the corpus } \\
\text { and ramus. }\end{array}$ \\
\hline Gnathion (Gn) & The midway between menton and pogonion. \\
\hline Condylion (Co) & The most superior posterior point on the condylar head. \\
\hline Porion (Po) & The most superior point of each external acoustic meatus. \\
\hline Is & The most incisal and labial point on the most protruded upper incisors. \\
\hline Ii & The most incisal and labial point on the most protruded lower incisors. \\
\hline U6 fur & The furcation of the upper right and left first molars. \\
\hline U6 ap & The most anterior point on the mesial surface of the upper right and left first molars. \\
\hline L6 fur & The furcation of the lower right and left first molars. \\
\hline L6 ap & The most anterior point on the mesial surface of the lower right and left first molars. \\
\hline Frankfort Horizontal plane (FHP) & A plane defined by 3 landmarks, right and left porion and left orbitale. \\
\hline Anterior cranial base line (SN) & A line passing through sella and nasion points. \\
\hline Mandibular plane (MP) & A plane that passes through menton and both gonion points (right and left). \\
\hline Nasion-vertical line (Nv) & A line from Nasion perpendicular to FHP. \\
\hline
\end{tabular}

\section{Statistical Analysis}

Data were collected, coded and analyzed with the Statistical Package for Social Science (SPSS) software for windows (SPSS Version 23, Inc., Chicago, Illinois, USA). The distribution of quantitative data was tested by Kolmogorov-Smirnov and Shapiro-Wilk tests of normality. Data were statistically described as mean, standard deviation, $95 \%$ confidence interval $(95 \% \mathrm{CI})$, standard error of mean, and mean differences i.e. T1-T2 changes. The data were then checked for pre-treatment equivalence between the two studied groups with independent sample t-test. Paired t-test was used to compare the changes within each group before (T1) and after TB therapy (T2). Additionally, independent sample ttest was used to compare between the two studied groups according to amount of change (T1-T2) in the analyzed variables. The significance level was set at $\mathrm{p} \leq 0.05$.

TABLE (2): Definitions of dentoskeletal measurements used in the study

\begin{tabular}{|l|l|}
\hline Measurement & \multicolumn{1}{c|}{ Definition } \\
\hline SNA $\left(^{\circ}\right)$ & $\begin{array}{l}\text { The angle between } 3 \text { landmarks S, N, and A points, determining the anteroposterior position of the maxilla } \\
\text { relative to the cranial base. }\end{array}$ \\
\hline SNB $\left(^{\circ}\right)$ & $\begin{array}{l}\text { The angle between } 3 \text { landmarks S, N, and B point, determining the anteroposterior position of the mandible } \\
\text { relative to the cranial base. }\end{array}$ \\
\hline ANB $\left(^{\circ}\right)$ & $\begin{array}{l}\text { The angle between 3 landmarks, A point, N and B point, determining the anteroposterior relation between } \\
\text { maxilla and the mandible relative to the cranium }\end{array}$ \\
\hline A-NV $(\mathrm{mm})$ & $\begin{array}{l}\text { The linear distance measured between point A and Nv line, measuring the anteroposterior position of the } \\
\text { maxilla relative to the nasion vertical line. }\end{array}$ \\
\hline B-NV $(\mathrm{mm})$ & $\begin{array}{l}\text { The linear distance measured between point B and Nv line, determining the anteroposterior position of the } \\
\text { mandible relative to the nasion vertical line. }\end{array}$ \\
\hline $\mathrm{N}-\mathrm{Me}(\mathrm{mm})$ & The linear distance between point N and point Me, for measure the anterior facial height. \\
\hline
\end{tabular}




\begin{tabular}{|l|l|}
\hline Measurement & \multicolumn{1}{|c|}{ Definition } \\
\hline S-Go $(\mathrm{mm})$ & $\begin{array}{l}\text { The linear perpendicular distance between point S and point Inter-Gonion line, for measure the posterior } \\
\text { facial height. }\end{array}$ \\
\hline Co-A $(\mathrm{mm})$ & The average of the bilateral linear distance between Co and A points, measuring the effective mid facial length. \\
\hline Co-Gn $(\mathrm{mm})$ & The linear distance between points Co and Gn, measuring the effective mandibular length. \\
\hline Co-Go $(\mathrm{mm})$ & The linear distance between points Co and Go, measuring the ramus length. \\
\hline Go-Gn $(\mathrm{mm})$ & The linear distance between points Go and Gn, measuring the corpus length. \\
\hline MP-FHP $\left(^{\circ}\right)$ & The angle between FHP and the MP. \\
\hline U1-FHP $\left(^{\circ}\right)$ & The angle formed between the FHP and the long axis of the most protruded upper incisor. \\
\hline L1-FHP $\left(^{\circ}\right)$ & The angle formed between the FHP and the long axis of the most protruded lower incisor. \\
\hline L1-MP $\left(^{\circ}\right)$ & The angle formed between the MP and the long axis of the most protruded lower incisor. \\
\hline U1-L1 $\left(^{\circ}\right)$ & The angle formed between UI and LI long axes. \\
\hline Overjet $(\mathrm{mm})$ & The difference between two measurements Is-Nv line and LIap-Nv line. \\
\hline Overbite $(\mathrm{mm})$ & The difference between two measurements Is-FHP and Ii-FHP \\
\hline U6-Nv $(\mathrm{mm})$ & The linear distance between U6ap and Nv line. \\
\hline L6-Nv $(\mathrm{mm})$ & The linear distance between L6ap and Nv line. \\
\hline U6-FHP $(\mathrm{mm})$ & The linear distance between U6 furcation and FHP \\
\hline L6-MP $(\mathrm{mm})$ & The linear distance between point L6 furcation and MP. \\
\hline
\end{tabular}

\section{RESULTS}

During the course of the study, 4 patients from each group ( 2 males and 2 females) were excluded from the study because of following reasons; noncompliance lost to follow-up laser application, poor oral hygiene, and no longer wanted treatment. However, the remaining 24 patients (12 females and 12 males) had completed the study.

Kolmogorov-Smirnov and Shapiro-Wilk tests show that the data was normally distributed. Accordingly, parametric tests were used for statistical evaluation. Systematic error was assessed with paired t-test, and random error was assessed with the coefficient of reliability between the first measurement (data of the total sample) and the $2^{\text {nd }}$ measurements. No statistically significant differences were found between $1^{\text {st }}$ and $2^{\text {nd }}$ measurements $(p>0.05)$.

\section{Comparison of lateral cephalometric dento- skeletal measurements before (T1) and after (T2) TB within each group:}

Tables (3\&4) show comparison of lateral cephalometric skeletal measurements before (T1) and after (T2) TB therapy in laser and control group using paired t-test. In both groups, there are no statistically significant differences $(p>0.05)$ in the anteroposterior maxillary position as revealed by $\mathrm{SNA}\left({ }^{\circ}\right), \mathrm{A}-\mathrm{NV}(\mathrm{mm})$ and Co-A $(\mathrm{mm})$ measurements after TB. However, there is statistically significant increase $(p \leq 0.05)$ in anteroposterior mandibular position as showed by ANB $\left(^{\circ}\right)$, SNB $\left(^{\circ}\right)$ and B-NV (mm) parameters. Similarly, the mandibular effective, ramus, and corpus lengths show statistically significant increases after TB therapy. Similarly, there are statistically significant increases $(\mathrm{p} \leq 0.01)$ in measurements of the anterior facial height (N-Me), the posterior facial height (S-Go) and MP-FHP angle.

Comparison of dental measurements at $\mathrm{T} 1$ and T2within laser and control groups using paired t-test showed that the upper incisors' inclination (U1FHP) was significantly decreased $(\mathrm{p} \leq 0.05)$ while the lower incisors' inclination (L1-FHP and L1-MP) and the interincisal angle (U1-L1) are significantly increased $(\mathrm{p} \leq 0.05)$. Also, there are statistically significant decreases $(\mathrm{p} \leq 0.05)$ in overjet $(\mathrm{mm})$ and overbite $(\mathrm{mm})$. 
On the other hand, there are no statistically significant difference $(p>0.05)$ in linear measurements of upper first molar position (U6-NV and U6-FHP). In contrast, there are statistically significant changes $(\mathrm{p} \leq 0.05)$ in lower first molar position L6-NV (mm) and L6-MP (mm) measurements.

\section{Comparison of changes in dentoskeletal (T1-} T2) measurements between laser and control groups using independent sample t-test.

Table (5) show comparison of changes (T1-T2) in dentoskeletal measurements between laser and control groups using independent sample t-test. The result show non-significant differences between both groups regarding all studied parameters $(\mathrm{p}>0.05)$.

TABLE (3): Comparison of dentoskeletal measurements before and after Twin-block therapy in the control group ( $\mathrm{N}=12)$ using paired $\mathrm{t}$-test:

\begin{tabular}{|c|c|c|c|c|c|c|c|c|c|c|}
\hline \multirow{2}{*}{ Measurement } & \multicolumn{2}{|c|}{ T1 } & \multicolumn{2}{|c|}{ T2 } & \multirow{2}{*}{$\begin{array}{c}\text { Mean } \\
\text { diff. } \pm \text { SE }\end{array}$} & \multicolumn{2}{|c|}{$95 \%$ CI. } & \multirow{2}{*}{ t-value } & \multirow{2}{*}{ p-value } & \multirow{2}{*}{ Sig } \\
\hline & Mean & SD & Mean & SD & & UL & $\mathbf{L L}$ & & & \\
\hline SNA $\left({ }^{\circ}\right)$ & 81.13 & 3.33 & 80.88 & 2.48 & $0.3 \pm 0.4$ & 0.5 & 0.1 & 0.693 & 0.503 & NS \\
\hline $\mathrm{SNB}\left({ }^{\circ}\right)$ & 73.29 & 3.05 & 76.83 & 2.54 & $3.5 \pm 0.5$ & 4.8 & 0.2 & 2.432 & 0.031 & $\mathrm{~S}$ \\
\hline ANB $\left(^{\circ}\right)$ & 7.83 & 1.61 & 4.54 & 1.03 & $3.7 \pm 1.4$ & 4.2 & 1.8 & 2.940 & 0.018 & HS \\
\hline A-NV (mm) & 2.31 & 0.51 & 2.03 & 0.30 & $0.3 \pm 0.2$ & 0.8 & 0.1 & 1.209 & 0.252 & NS \\
\hline B-NV(mm) & 7.82 & 1.04 & 9.51 & 2.17 & $2.3 \pm 0.8$ & 3.1 & 1.1 & 2.407 & 0.012 & $\mathrm{~S}$ \\
\hline $\mathrm{N}-\mathrm{Me}(\mathrm{mm})$ & 104.3 & 6.5 & 106.5 & 6.5 & $2.3 \pm 0.4$ & 3.3 & 1.4 & 5.592 & $0.001^{* *}$ & HS \\
\hline S-Go (mm) & 63.0 & 5.0 & 64.3 & 5.9 & $1.3 \pm 0.5$ & 2.1 & 0.6 & 2.675 & $0.022 *$ & $\mathrm{~S}$ \\
\hline Co-A (mm) & 76.66 & 5.83 & 66.67 & 5.17 & $1.7 \pm 0.7$ & 1.9 & 0.5 & 2.950 & 0.113 & NS \\
\hline Co-Gn (mm) & 94.38 & 6.51 & 97.71 & 6.30 & $2.8 \pm 0.4$ & 3.1 & 1.3 & 7.974 & $0.001 *$ & HS \\
\hline Co-Go (mm) & 44.87 & 3.55 & 46.44 & 3.76 & $1.6 \pm 0.4$ & 2.4 & 0.8 & 4.388 & $0.001 * *$ & HS \\
\hline Go-Gn (mm) & 62.73 & 4.88 & 64.76 & 4.52 & $1.3 \pm 0.4$ & 1.8 & 0.6 & 4.750 & $0.001 *$ & HS \\
\hline MP-FHP $\left(^{\circ}\right)$ & 19.18 & 3.89 & 22.43 & 1.92 & $3.2 \pm 0.5$ & 4.3 & 1.8 & 0.497 & $0.001 * *$ & HS \\
\hline U1-FHP $\left(^{\circ}\right)$ & 119.8 & 7.17 & 115.6 & 6.89 & $4.4 \pm 1.1$ & 5.2 & 2.2 & 3.064 & $0.011 *$ & $\mathrm{~S}$ \\
\hline L1-FHP $\left(^{\circ}\right)$ & 53.04 & 5.10 & 48.28 & 4.67 & $7.4 \pm 0.8$ & 8.64 & 4.6 & 4.158 & $0.014 * *$ & HS \\
\hline L1-MP $\left(^{\circ}\right)$ & 94.81 & 4.78 & 99.3 & 4.37 & $5.1 \pm 0.8$ & 6.3 & 2.4 & 2.987 & 0.024 & $S$ \\
\hline U1-L1 $\left(^{\circ}\right)$ & 113.0 & 8.63 & 119.6 & 10.11 & $5.8 \pm 1.2$ & 6.3 & 3.2 & 2.899 & $0.014 * *$ & HS \\
\hline Overjet (mm) & 7.63 & 2.47 & 3.12 & 1.63 & $3.6 \pm 0.8$ & 4.9 & 1.4 & 3.217 & $0.008 * *$ & HS \\
\hline Overbite (mm) & 5.82 & 2.04 & 2.71 & 1.78 & $3.1 \pm 0.6$ & 3.5 & 1.2 & 3.146 & 0.005 & S \\
\hline U6-NV (mm) & 21.40 & 3.19 & 21.94 & 3.74 & $0.3 \pm 0.4$ & 1.1 & 0.1 & 0.250 & 0.237 & NS \\
\hline L6-NV (mm) & 22.91 & 3.20 & 20.72 & 3.55 & $2.1 \pm 0.5$ & 3.1 & 1.2 & 3.440 & $0.028^{*}$ & $\mathrm{~S}$ \\
\hline U6-FHP (mm) & 27.54 & 3.11 & 27.89 & 2.93 & $0.4 \pm 0.3$ & 0.5 & 0.4 & 0.441 & 0.668 & NS \\
\hline L6-MP (mm) & 15.95 & 2.28 & 17.13 & 2.51 & $1.6 \pm 0.2$ & 1.9 & 0.9 & 3.312 & $0.041^{*}$ & $\mathrm{~S}$ \\
\hline
\end{tabular}

$S E=$ Standard error, $P=$ Probability level, NS= Non significant $p>0.05, S=$ statistically significant at $p \leq 0.05, H S=$ highly significant at $p \leq 0.01, S D=$ standard deviation, $C I=$ Confidence interval, $U L=$ upper limit, $L L=$ lower limit. 
TABLE (4): Comparison of dentoskeletal measurements before and after Twin-block therapy in the laser group $(\mathrm{N}=12)$ using paired $\mathrm{t}$-test:

\begin{tabular}{|c|c|c|c|c|c|c|c|c|c|c|}
\hline \multirow{2}{*}{ Measurement } & \multicolumn{2}{|c|}{ T1 } & \multicolumn{2}{|c|}{ T2 } & \multirow{2}{*}{$\begin{array}{c}\text { Mean } \\
\text { diff. } \pm \text { SE }\end{array}$} & \multicolumn{2}{|c|}{ 95\% CI. } & \multirow{2}{*}{ t-value } & \multirow{2}{*}{ p-value } & \multirow{2}{*}{ Sig. } \\
\hline & Mean & SD & Mean & SD & & UL & $\mathbf{L L}$ & & & \\
\hline SNA $\left(^{\circ}\right)$ & 81.47 & 2.89 & 80.68 & 2.68 & $0.4 \pm 0.5$ & 0.9 & 0.2 & 0.683 & 0.533 & NS \\
\hline $\mathrm{SNB}\left({ }^{\circ}\right)$ & 73.74 & 2.94 & 76.83 & 2.54 & $3.6 \pm 0.4$ & 4.7 & 0.1 & 2.332 & $0.041 *$ & $\mathrm{~S}$ \\
\hline ANB $\left(^{\circ}\right)$ & 7.83 & 1.42 & 4.54 & 1.03 & $3.8 \pm 1.3$ & 4.3 & 1.7 & 2.840 & $0.028^{*}$ & S \\
\hline A-NV (mm) & 2.42 & 0.33 & 2.13 & 0.30 & $0.5 \pm 0.1$ & 0.8 & 0.2 & 1.200 & 0.352 & NS \\
\hline $\mathrm{B}-\mathrm{NV}(\mathrm{mm})$ & 7.82 & 1.04 & 9.51 & 2.17 & $2.4 \pm 0.7$ & 3.2 & 1.3 & 2.907 & $0.004 * *$ & HS \\
\hline $\mathrm{N}-\mathrm{Me}(\mathrm{mm})$ & 104.1 & 7.1 & 105.5 & 7.4 & $2.4 \pm 0.2$ & 3.2 & 1.4 & 4.592 & $0.001 * *$ & HS \\
\hline S-Go (mm) & 62.0 & 5.1 & 63.3 & 5.8 & $1.2 \pm 0.6$ & 2.2 & 0.6 & 2.645 & $0.032 *$ & $\mathrm{~S}$ \\
\hline Co-A (mm) & 76.32 & 5.17 & 77.47 & 5.27 & $1.6 \pm 0.8$ & 1.9 & 0.5 & 1.950 & 0.123 & NS \\
\hline Co-Gn (mm) & 94.18 & 5.79 & 97.71 & 6.30 & $2.9 \pm 0.2$ & 3.4 & 1.5 & 6.874 & $<0.001 * *$ & HS \\
\hline Co-Go (mm) & 44.57 & 3.49 & 46.44 & 3.76 & $1.8 \pm 0.2$ & 2.7 & 0.8 & 5.398 & $<0.001 * *$ & HS \\
\hline Go-Gn (mm) & 62.99 & 4.98 & 64.86 & 4.42 & $1.4 \pm 0.3$ & 1.9 & 0.5 & 4.150 & $<0.001^{*}$ & HS \\
\hline MP-FHP $\left(^{\circ}\right)$ & 19.78 & 3.29 & 22.83 & 1.92 & $3.1 \pm 0.7$ & 4.9 & 1.6 & 2.497 & 0.031 & S \\
\hline U1-FHP $\left(^{\circ}\right)$ & 120.2 & 6.79 & 115.7 & 6.78 & $4.5 \pm 1.2$ & 5.3 & 2.3 & 4.010 & $0.002 *$ & $\mathrm{~S}$ \\
\hline L1-FHP $\left(^{\circ}\right)$ & 54.35 & 4.36 & 49.91 & 4.69 & $7.5 \pm 0.9$ & 8.71 & 4.7 & 2.992 & $0.015^{*}$ & $\mathrm{~S}$ \\
\hline L1-MP $\left(^{\circ}\right)$ & 94.98 & 4.64 & 99.94 & 4.28 & $5.3 \pm 0.9$ & 6.74 & 2.2 & 2.468 & $0.030^{*}$ & S \\
\hline U1-L1 $\left(^{\circ}\right)$ & 115.8 & 9.14 & 119.1 & 7.91 & $5.2 \pm 1.3$ & 6.8 & 3.7 & 2.746 & $0.018^{*}$ & $\mathrm{~S}$ \\
\hline Overjet (mm) & 7.89 & 2.56 & 3.34 & 1.99 & $3.7 \pm 0.9$ & 4.8 & 2.3 & 4.507 & $0.001^{*}$ & HS \\
\hline Overbite (mm) & 5.86 & 2.05 & 2.61 & 1.82 & $3.2 \pm 0.5$ & 5.1 & 1.6 & 3.778 & 0.004 & HS \\
\hline U6-NV (mm) & 21.22 & 3.14 & 21.34 & 3.69 & $0.4 \pm 0.3$ & 1.2 & 0.2 & 0.751 & 0.467 & NS \\
\hline L6-NV (mm) & 22.42 & 3.41 & 22.25 & 3.69 & $1.9 \pm 0.7$ & 3.2 & 1.1 & 3.533 & $0.024 *$ & S \\
\hline U6-FHP (mm) & 27.89 & 3.12 & 27.93 & 3.02 & $0.3 \pm 0.2$ & 0.6 & 0.2 & 1.021 & 0.327 & NS \\
\hline L6-MP (mm) & 15.69 & 2.43 & 17.45 & 2.71 & $1.7 \pm 0.3$ & 2.1 & 0.8 & 2.969 & $0.045^{*}$ & $\mathrm{~S}$ \\
\hline
\end{tabular}

$S E=$ Standard error, $P=$ Probability level, NS= Non significant $p>0.05, S=$ statistically significant at $p \leq 0.05$, $H S=$ highly significant at $p \leq 0.01, S D=$ standard deviation, $C I=$ Confidence interval, $U L=$ upper limit, $L L=$ lower limit .

TABLE (5): Comparison of changes (T1-T2) in dentoskeletal measurements between laser and control groups using independent sample t-test

\begin{tabular}{|l|c|c|c|c|c|c|}
\hline \multirow{2}{*}{ Measurement } & \multicolumn{2}{|c|}{$\begin{array}{c}\text { Control } \\
\text { group } \\
(\mathbf{n}=\mathbf{1 2})\end{array}$} & \multicolumn{2}{|c|}{$\begin{array}{c}\text { Laser group } \\
(\mathbf{n}=\mathbf{1 2})\end{array}$} & \multirow{2}{*}{ p-value } & \multirow{2}{*}{ Sig. } \\
\cline { 2 - 5 } & Mean & SE & Mean & SE & & \\
\hline SNA $\left(^{\circ}\right)$ & 0.3 & 0.4 & 0.4 & 0.5 & 0.347 & NS \\
\hline SNB $\left(^{\circ}\right)$ & 3.5 & 0.5 & 3.6 & 0.4 & 0.728 & NS \\
\hline ANB $\left(^{\circ}\right)$ & 3.7 & 1.4 & 3.8 & 1.3 & 0.728 & NS \\
\hline A-NV $(\mathrm{mm})$ & 0.3 & 0.2 & 0.5 & 0.1 & 0.894 & NS \\
\hline B-NV $(\mathrm{mm})$ & 2.3 & 0.8 & 2.4 & 0.7 & 0.689 & NS \\
\hline N-Me $(\mathrm{mm})$ & 2.3 & 0.4 & 2.4 & 0.2 & 0.295 & NS \\
\hline S-Go $(\mathrm{mm})$ & 1.3 & 0.5 & 1.2 & 0.6 & 0.123 & NS \\
\hline Co-A $(\mathrm{mm})$ & 1.7 & 0.7 & 1.6 & 0.8 & 0.247 & NS \\
\hline Co-Gn $(\mathrm{mm})$ & 2.8 & 0.4 & 2.9 & 0.2 & 0.689 & NS \\
\hline
\end{tabular}

\begin{tabular}{|l|c|c|c|c|c|c|}
\hline Co-Go $(\mathrm{mm})$ & 1.6 & 0.4 & 1.8 & 0.2 & 0.406 & NS \\
\hline Go-Gn $(\mathrm{mm})$ & 1.3 & 0.4 & 1.4 & 0.3 & 0.376 & NS \\
\hline MP-FHP $\left(^{\circ}\right)$ & 3.2 & 0.5 & 3.1 & 0.7 & 0.728 & NS \\
\hline U1-FHP $\left({ }^{\circ}\right)$ & 4.4 & 1.1 & 4.5 & 1.2 & 0.728 & NS \\
\hline L1-FHP $\left(^{\circ}\right)$ & 7.4 & 0.8 & 7.5 & 0.9 & 0.689 & NS \\
\hline L1-MP $\left(^{\circ}\right)$ & 5.1 & 0.8 & 5.3 & 0.9 & 0.689 & NS \\
\hline U1-L1 $\left(^{\circ}\right)$ & 5.8 & 1.2 & 5.2 & 1.3 & 0.574 & NS \\
\hline Overjet $(\mathrm{mm})$ & 3.6 & 0.8 & 3.7 & 0.9 & 0.295 & NS \\
\hline Overbite $(\mathrm{mm})$ & 3.1 & 0.6 & 3.2 & 0.5 & 0.728 & NS \\
\hline U6-NV $(\mathrm{mm})$ & 0.3 & 0.4 & 0.4 & 0.3 & 0.979 & NS \\
\hline L6-NV $(\mathrm{mm})$ & 2.1 & 0.5 & 1.9 & 0.7 & 0.852 & NS \\
\hline U6-FHP $(\mathrm{mm})$ & 0.4 & 0.3 & 0.3 & 0.2 & 0.894 & NS \\
\hline L6-MP $(\mathrm{mm})$ & 1.6 & 0.2 & 1.7 & 0.3 & 0.728 & NS \\
\hline
\end{tabular}

$S E=$ Standard error, mm=millimeters, $P=$ Probabil ity level, $N S=$ Non significance $p>0.05, N=$ Number, Sig=Significant . 


\section{DISCUSSION}

Class II malocclusion appears with high frequency and constitutes a significant proportion of patients seeking orthodontic treatment. A variety of factors contribute to the development of Class II malocclusion and their differential diagnosis can help in the selection of the most appropriate treatment approach. Among these factors, mandibular retrognathism shows a prevailing frequency as main contributor to Class II malocclusion ${ }^{(1,2)}$. In this study, all participated patients were treated with Twin-block (TB) functional appliance, according to the decided treatment plan, as a first stage for skeletal Class II patients with mandibular retrognathism ${ }^{(1,2)}$. To evaluate the pure effects of functional appliances, fixed appliances were not inserted during the retention phase using the same functional appliance.

The present inclusion criteria were based on several previous studies ${ }^{(5,7,8,11)}$. In the present investigation, TB functional appliance was chosen because it includes upper and lower acrylic bite blocks that is generally tolerated by most of patients due to its smaller size, no visible acrylic portion anteriorly, and its minimal interference with speech ${ }^{(1)}$.

The assessment of skeletal age was performed via the evaluation of cervical vertebral maturation stages (CVMS), according to the modified method of Baccetti et $\mathrm{al}^{(26)}$. They suggested that the optimal treatment timing for TB therapy is during or slightly after the onset of the pubertal peak in growth velocity. Consequently, the current patients of both groups were selected to be at stage II and III of the modified CVMS that show the initiation and peak of growth spurt, respectively, order to achieve maximum therapeutic effects of TB appliances.

In the present investigation, TB appliance was constructed with the incisors in an end-toend position in accordance with several previous reports ${ }^{(5,7,8,11,12)}$. Interestingly, Banks et $\mathrm{al}^{(27)}$ found that there was no difference between incremental bite advancement and maximum advancement during bite registration. Moreover, treatment interval with $\mathrm{TB}$, in the reviewed reports, had a wide variety ranging from 8 to 16 months ${ }^{(1-3)}$. For this reason, in the present study, the active TB therapy in both groups was extended for 9 months ${ }^{(5)}$.

The patients undergoing orthodontic treatment often complain about the length of treatment time ${ }^{(18)}$. Recently, low-level laser has been used to promote bone healing after fracture, after mandibular distraction osteogenesis, for stimulating condylar cartilage and to reduce functional treatment time $\mathrm{e}^{(19-21)}$.

To the present knowledge, no human data is available concerning this issue. Therefore, it was a matter of interest to evaluate the effect of LLLT on dentoskeletal during functional treatment of skeletal class II malocclusions. The present protocol of LLLT was selected addiction modality for management of TMD because it is clinically accepted with a wavelength of $635 \mathrm{~nm}$ and energy of $50 \mathrm{mw}$ that was directly applied on the right and left sides on five points around the TMJ for 12 sessions at three months ${ }^{(24,25)}$.

\section{Skeletal and dental effects of Twin-Block thera- py with and without LLLT:}

In the current study, lateral cephalometric images were reconstructed from the CBCT images, obtained at T1and $\mathrm{T} 2$, to assess the dentoskeletal changes following TB therapy in both groups, with and without LLLT, in accordance with other studies $^{(5)}$.

\section{A. Sagittal skeletal changes:}

Functional appliances were proposed to produce a distally directed force to maxilla as the mandible repositioned forward ${ }^{(1-3)}$.However, in the available literature, controversial results exist for the restraining effect of TB therapy on maxilla. In contrast, some studies showed maxillary restriction following TB functional therapy ${ }^{(5-13,15,16)}$ and some studies did not establish such finding ${ }^{(4,14)}$. 
In the current study, compared with the baseline values, there were non-significant changes in the effective maxillary length, the sagittal maxillary position evaluated by SNA angle and A-Nv measurements in both groups, with and with laser. These results do not advocate any significant headgear effect associated with TB therapy. Analogous results were also emphasized by Clark $^{(4)}$ and Illing et al ${ }^{(14)}$ and the three-dimensional studies of Elfeky et $\mathrm{al}^{(5)}$ and Vedavathiet $\mathrm{al}^{(6)}$ without LLLT.

However, the current findings are not compatible with those of Lund and Sandler, ${ }^{(9)}$ Mills and McCulloch, ${ }^{(10)} \mathrm{O}$ 'Brien et al, ${ }^{(12)}$ Toth and McNamara ${ }^{(15)}$ and Trenouth ${ }^{(16)}$.In these reports, it is not clear that whether their sample included Cass II patients with normal maxillary dimensions. Furthermore, their appliance design could affect the comparison with the findings.

In the present research, on the other hand, an improvement in the mandibular retrognathism could also be demonstrated by in both groups following 9 months of TB therapy. The effective mandibular length was considerably increased by $2.9 \mathrm{~mm}$ and 2.8 $\mathrm{mm}$, in both laser and control groups, respectively, which are desirable outcomes of functional therapy. Also, the ramus length was augmented by an average $1.7 \mathrm{~mm}$ and $1.6 \mathrm{~mm}$, respectively, in the laser and control groups. In addition, corpus length showed an added increase of average $1.4 \mathrm{~mm}$ and $1.3 \mathrm{~mm}$ in both groups, respectively.

Other authors also reported significant extramandibular augmentation with TB appliance without laser. In accordance with current findings, Vedavathi et $\mathrm{al}^{(6)}$ reported similar increases in condylion-gnathion measurements after TB therapy. Correspondingly, Baysal and Uysal ${ }^{(13)}$ reported that TB therapy resulted in an additional $3.37 \mathrm{~mm}$ increase in effective mandibular length. Moreover, after 12-16 months of TB therapy, increases of 1.46 to $4.75 \mathrm{~mm}$ in mandibular length was also reported by Elfeky et al ${ }^{(5)}$ Bacetti et al,${ }^{(7)}$ Jena et al,${ }^{(8)}$ Lund and Sandler, ${ }^{(9)}$ Mills and McCulloch, ${ }^{(10)}$ O’Brien et al, ${ }^{(12)}$ Illing et al, ${ }^{(14)}$ and Toth and McNamara ${ }^{(15)}$. Additionally, Jena and Duggal ${ }^{(11)}$ found compatible results of $1.98 \mathrm{~mm}$ extra-mandibular augmentation.

In addition, the current enhanced mandibular skeletal changes, in both groups, could be attributed to the observed significant changes in the mandibular position as evidenced by the favorable changes in $\mathrm{SNB}$ angle and B-Nv measurements. The average changes were $3.6^{\circ}$ in the laser group, $3.5^{\circ}$ in the control group, $2.4 \mathrm{~mm}$ in the laser one, and $2.3 \mathrm{~mm}$ in the control one for the B-Nv distance. Interestingly, these findings, over a shorter treatment period, are in concurrence with other studies that showed comparable outcomes following TB therapy, without laser, which is clinically advantageous to patients with mandibular retrognasim ${ }^{(5-16)}$.

In general, the majority of above mentioned studies observed noteworthy increases compared with untreated control groups. Once more, it is important to note that the present values were dependable on comparison with pre-treatment parameters. However, the effect of natural growth must be considered. In the present study, nevertheless, the inclusion of untreated control group was difficult for ethical reasons. Moreover, according to the available knowledge, there is no published 3D information among Egyptians that could explain the natural growth changes in this regard.

In the present study, when inter-jaw relations were evaluated, the treatment effects were mainly produced by mandibular changes because maxillary measurements were not affected by the TB therapy in both groups, with and without LLLT. The current results clarified a noteworthy improvement of the facial profile through the observed significant reduction in the $\mathrm{ANB}^{\circ}$ angle in both laser and control groups by averages $3.8^{\circ}$ and $3.7^{\circ}$, respectively. These results are in harmony with numerous investigations ${ }^{(5-16)}$.

Despite the fact that restraining effect on the maxilla could not be demonstrated, the present 
forward growth/repositioning of the mandible could contribute to the significant change in ANB angle hence the severity of the Class II skeletal pattern was reduced.

\section{B. Vertical skeletal changes:}

In the present study, there are improvements of the reduced anterior vertical dimensions following TB therapy in both groups, with and without laser. These were manifested by the sizeable increases in the angular vertical skeletal assessments were increased as evidenced by increased MP-FHP angle by $3.1^{\circ}$ and $3.2^{\circ}$ in the laser and control groups, respectively. Likewise, there are major increases in anterior facial facial height. Yet again, these findings must be interpreted with caution due to the possible growth affect as these findings are presented in comparison with pre-treatment values.

Nevertheless, the comparisons of the abovementioned changes illustrate no significant differences between both groups with and without laser application. So, it may be fulfilled that valuable vertical skeletal changes could be achieved with TB therapy regardless the presence of LLLT.

\section{Dental changes:}

In the current study, the included upper labial arch resulted in palatal tipping of the maxillary incisors by $4.5^{\circ}$ in the laser group and $4.4^{\circ}$ in the control one. Jena and Duggal ${ }^{(11)}$ also found compatible results after TB therapy. Regarding the mandibular incisors, significant proclination was evident after TB therapy, with and without LLLT, compared with the pre-treatment values in spite of the incorporated lower labial bow. They were tipped labially by $7.5^{\circ}$ in the laser group and $7.4^{\circ}$ in the control one. This change might be due to the mesial force on the mandibular incisors induced by the forward posture of the mandible as explained by several authors ${ }^{(5,8,9)}$.

The current findings concur with many previous reports that considered the proclination of mandibular incisors as the most prominent dentoalveolar effect of several functional appliances including the TB. In the literature, $2^{\circ}-7.9^{\circ}$ increases in lower incisor proclination were reported after TB appliance therapy using conventional cephalometric assessment $^{(5,9,12,14,16)}$.

In accordance with current results, Mills and McCulloch $^{(10)}$ and Toth and McNamara ${ }^{(15)}$ used TB appliance with a labial bow similar to the present one in order to control lower incisor proclination. They reported that lower incisor proclination was significantly increased after TB therapy. Additionally, Lund and Sandler ${ }^{(9)}$ found significant lower incisor proclination after TB therapy compared with a control group. As well, Elfeky et al,${ }^{(5)} \mathrm{O}^{\prime}$ Brien et al, ${ }^{(12)}$ Illing et al, ${ }^{(15)}$ and Trenouth ${ }^{(16)}$ reported equivalent findings to the present study. There was a high degree of variability with these tipping movements that in conjunction with the forward growth/repositioning of the mandible were responsible for a statistically significant reduction in the overjet.

Presently, as a result of TB therapy, the overjet was decreased significantly in both groups, with and without laser therapy. It was reduced by an average $3.7 \mathrm{~mm}$ in the laser group and $3.6 \mathrm{~mm}$ in the control one. In agreement with the current findings, Mills and $\mathrm{McCulloch}^{(10)}$ reported that $50 \%$ of overjet correction was due to skeletal changes after TB appliance. However, Jena and Duggal ${ }^{(11)}$ suggested that $59.94 \%$ skeletal change was contributed to the overjet correction. Nevertheless, O'Brien et $\mathrm{al}^{(12)}$ reported only $27 \%$ skeletal change donated in overjet correction. Concerning the overbite, it was also enhanced by an average $3.2 \mathrm{~mm}$ in the laser group and $3.1 \mathrm{~mm}$ in the control one.

In the current study, there was an increased eruption of the lower molars during treatment after careful trimming of the maxillary bite blocks. This differential lower molar eruption is an important feature in TB therapy as it not only contributes to overbite reduction and closure of lateral open bites but also assists for Class II molar correction. 
However, the inter-group comparison revealed no major difference for these dental changes between laser-treated and non-treated groups.

One limitations of the current study could be the absence of untreated control group to confirm the present findings and to exclude any possible effects of the natural growth pattern. As well, possible gender difference and the short-term basis of the study necessitate further long-term investigations. The currently-used laser protocol was based on the recommendation for treatment of TMD for only 3 months of TB therapy. Difference results could be achieved if anther protocol with different parameters is utilized in future clinical studies.

\section{CONCLUSION}

1. Combination of LLLT, with the current parameters and application's protocol, accomplished no considerable skeletal and dentoalveolar effects after functional orthopaedic treatment of skeletal Class II malocclusion with TB appliance.

2. Twin-Block therapy resulted in considerable mandibular skeletal changes in both dimensions and positions with improvement of the skeletal profile in both anteroposterior and vertical directions.

3. Substantial dentoalveolar changes are evident after TB therapy with improvement of overjet and molar relation regardless the existence of LLLT.

\section{REFERENCES}

1. Ehsani S, Nebbe B, Normando D, Lagravere MO, FloresMir C. Short term treatment effects produced by the Twinblock appliance: a systematic review and meta-analysis. Eur J Orthod 2014;37:170-6.

2. Perinetti G, Primožič J, Franchi L, Contardo L. Treatment effects of removable functional appliances in pre-pubertal and pubertal Class II patients: a systematic review and meta-analysis of controlled studies. PLoS One 2015;10:1-35.

3. Santamaría-Villegas A, Manrique-Hernandez R, AlvarezVarela E, Restrepo-Serna C. Effect of removable function- al appliances on mandibular length in patients with class II with retrognathism: systematic review and meta-analysis. BMC Oral Health 2017;17:52-61.

4. Clark W. The Twin-block technique: A functional orthopedic appliance system. Am J Orthod Dentofacial Orthop 1988;93:1-8.

5. Elfeky HY, Fayed MS, Alhammadi MS, Soliman SA, El Boghdadi DM. Three-dimensional skeletal, dentoalveolar and temporomandibular joint changes produced by Twin Block functional appliance. J Orofac Orthop 2018;16:114.

6. Vedavathi H, Arora-Chirag K. Comparative assessment of condylar changes in patients treated with TB appliance: A cone-beam computed tomography study. IOSR-J Dent Medi Sci 2016;15:b1-7.

7. Baccetti T, Franchi L, Toth L, McNamara J. Treatment timing for Twin-block therapy. Am J Orthod Dentofacial Orthop 2000; 118:159-70.

8. Jena A, Duggal R, Parkash H. Skeletal and dentoalveolar effects of Twin-block and bionator appliances in the treatment of Class II malocclusion: a comparative study. Am J Orthod Dentofacial Orthop 2006;130:594-602.

9. Lund D, Sandler P. The effects of Twin block: a prospective controlled study. Am J Orthod Dentofacial Orthop 1998;113:104-10

10. Mills C, McCulloch K. Treatment effects of the Twinblock appliance: a cephalometric study. Am J Orthod Dentofacial Orthop 1998;114:15-24.

11. Jena A, Duggal R. Treatment effects of twin-block and mandibular protraction appliance-IV in the correction of class II malocclusion. Angle Orthod 2010;80:485-91.

12. O'Brien K, Wright J, Conboy F, Sanjie Y, Mandall N, Chadwick $S$, et al. Effectiveness of early orthodontic treatment with the Twin-block appliance: a multicenter, randomized, controlled trial. Part 1: dental and skeletal effects. Am J Orthod Dentofacial Orthop 2003; 124:234-43.

13. Baysal A, Uysal T. Dentoskeletal effects of Twin-block and Herbst appliances in patients with Class II division 1 mandibular retrognathy. Eur J Orthod 2013;36:164-72.

14. Illing H, Morris D, Lee R. A prospective evaluation of Bass, Bionator and Twin Block appliances. Part I-The hard tissues. Eur J Orthod 2005;20:501-16.

15. Toth L, McNamara J. Treatment effects produced by the Twin-block appliance and the FR-2 appliance of Fränkel compared with an untreated Class II sample. Am J OrthodDentofacialOrthop 1999;116:597-609. 
16. Trenouth M. Cephalometric evaluation of the Twin-block appliance in the treatment of Class II Division 1 malocclusion with matched normative growth data. Am J Orthod Dentofacial Orthop 2000;117:54-59.

17. Oksayan R, Ciftci M, Aktan A, Sokucu O. Biostimulation of mandibular condyle growth. J Ortho Res 2015;3: 147-50.

18. Abtahi M, Poosti M, Saghravanian N, Sadeghi K, Shafaee $\mathrm{H}$. The effect of low level laser on condylar growth during mandibular advancement in rabbits. Head Face Med 2012;8:4-8

19. El-Bialy T, Alhadlaq A, Felemban N, Yeung J, Ebrahim A, Hassan A. The effect of light-emitting diode and laser on mandibular growth in rats. Angle Orthod 2015;85:233-38.

20. Saafan A, Abd-El-Fattah A, Bakeer A, Khattab S.M. Effect of low power diode laser on mandibular growth (experimental study). J Dent Lasers 2014;8:50-55.

21. Seifi M, Maghzi A, Gutknecht N, Mir M, Asna-Ashari M. The effect of $904 \mathrm{~nm}$ low level laser on condylar growth in rats. Lasers Med Sci 2010;25:61-65.
22. Bashardoust S, Macdermid JC, Houghton P, Grewal R. Effects of low power laser irradiation on bone healing in animals: a meta-analysis. Orthop Surg Res 2010;5:1-7

23. Miloro M, Miller JJ, Stoner JA. Low-level laser effect on mandibular distraction osteogenesis. J Oral Maxillofac Surg 2007; 65:168-76.

24. Carrasco TG, Mazzetto MO, Mazzetto RG, Mestriner W. Low intensity laser therapy in temporomandibular disorder: a phase II double-blind study. Cranio 2008; 26:274-81.

25. Ferreira L, de Oliveira R, Guimaraes J, Carvalho A, De Paula M. Laser acupuncture in patients with temporomandibular dysfunction: a randomized controlled trial. Lasers Med Sci 2013; 28:1549-58.

26. Baccetti T, Franchi L, McNamara JA. An improved version of the cervical vertebral maturation (CVM) method for the assessment of mandibular growth. Angle Orthod 2002; 72:316-23.

27. Banks $\mathrm{P}$, Wright $\mathrm{J}$, O'Brien $\mathrm{K}$. Incremental versus maximum bite advancement during twin-block therapy: a randomized controlled clinical trial. Am J Orthod Dentofacial Orthop 2004; 126:583-88. 